
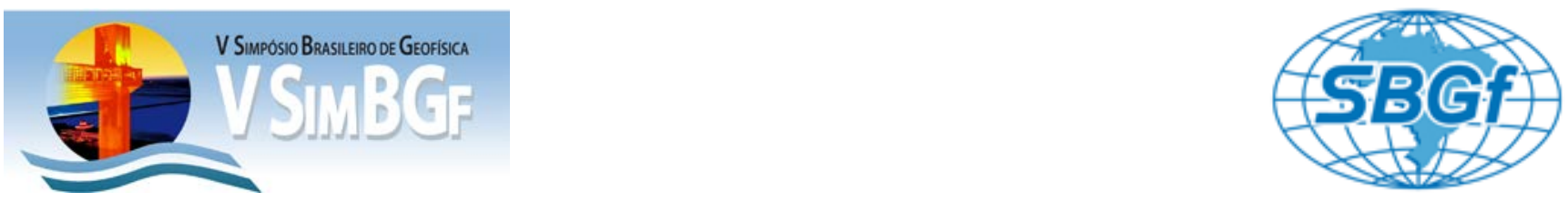

\title{
Variações Geomagnéticas na Região do Eletrojato Equatorial, a partir da estação de Capitão Poço
}

Larissa da Silva Piauilino e Luiz Benyosef, Observatório Nacional

Copyright 2012, SBGf - Sociedade Brasileira de Geofísica

Este texto foi preparado para a apresentação no $V$ Simpósio Brasileiro de Geofísica, Salvador, 27 a 29 de novembro de 2012. Seu conteúdo foi revisado pelo Comitê Técnico do $V$ SimBGf, mas não necessariamente representa a opinião da SBGf ou de seus associados. É proibida a reprodução total ou parcial deste material para propósitos comerciais sem prévia autorização da SBGf.

\section{Resumo}

Capitão Poço está localizado no estado do Pará, à sudeste da capital Belém, na região do eletrojato equatorial. Este estudo tem como objetivo selecionar dados da componente horizontal $\mathrm{H}$ e vertical $\mathrm{Z}$, do campo geomagnético registrados na região deste município, caracteriza-los e correlaciona-los com registros de dois observatórios magnéticos situados em diferentes latitudes.

\section{Introdução}

A dinâmica do equador magnético $(\mathrm{dip}=0)$ é bastante dinâmica especialmente sobre o território brasileiro conforme pode ser visto na figura 1 comparativamente com sua evolução em outras partes do mundo. A figura ilustra a variação do equador magnético nos últimos cem anos.

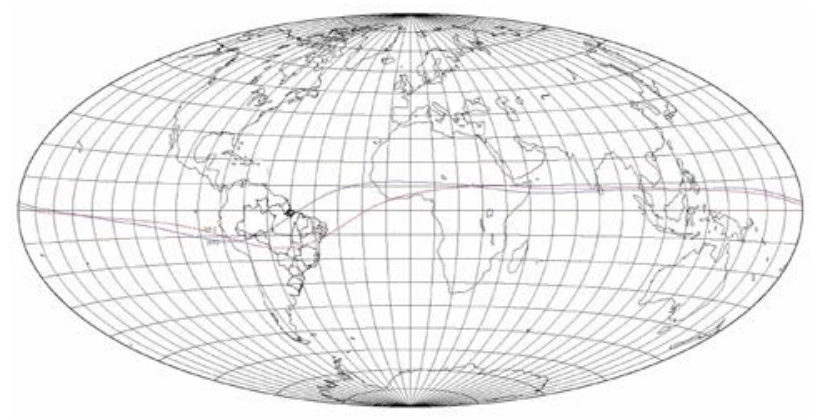

Figura 1 - Variação da inclinação magnética entre 1912 e 2012. Fonte: ON.

Este estudo tem por meta analisar registros de uma estação magnética ocupada pelo grupo de geomagnetismo do Observatório Nacional, analisando primeiramente as variações magnéticas rápidas e identificando os fenômenos característicos, especialmente dos tipos SSC e SI, para posteriormente verificar as correlações com registros de outros locais de medição previamente selecionados. Pela comparação e análise dos resultados pretende-se, neste trabalho de iniciação cientifica, melhor compreender a dinâmica fenomenológica envolvida.

\section{As estações de comparação}

A estação de referência para este trabalho é Capitão Poço, situada em latitude 0144'05.43"S e longitude: $47^{\circ} 03^{\prime} 43.72^{\prime \prime} \mathrm{W}$ e a uma altitude média de 80 metros. Para este estudo foi considerado a ocupação no período de 13 a 27 de novembro de 2008. O instrumento utilizado foi um magnetômetro fluxgate, triaxial, LEMI-417, com os sensores enterrados a aproximadamente 1 metro da superfície. Para o alinhamento foi escolhido as coordenadas $(H, D, Z)$ do campo magnético local e os registros com período segundos. Entretanto os dados foram transformados em formato IAGA com período de 1 minuto.

Neste estudo estão tendo maior atenção as variações magnéticas com períodos entre 1 e 17 minutos. Na primeira parte deste estudo foram analisadas as variações de $\mathrm{H}$ e $\mathrm{Z}$ registradas em Capitão Poço classificando-as quanto a sua fenomenologia e depois comparadas com registros de dois observatórios magnéticos também situados em baixas latitudes, Tatutoca (TTB) situado em latitude: 01012'18'S, longitude: 48 $30^{\prime} 46^{\prime \prime O}$ e Ascencion Island (ASC), latitude: $07^{\circ} 55^{\prime} 20^{\prime \prime} \mathrm{S}$ e longitude: $14^{\circ} 25^{\prime} 30^{\prime \prime} \mathrm{O}$

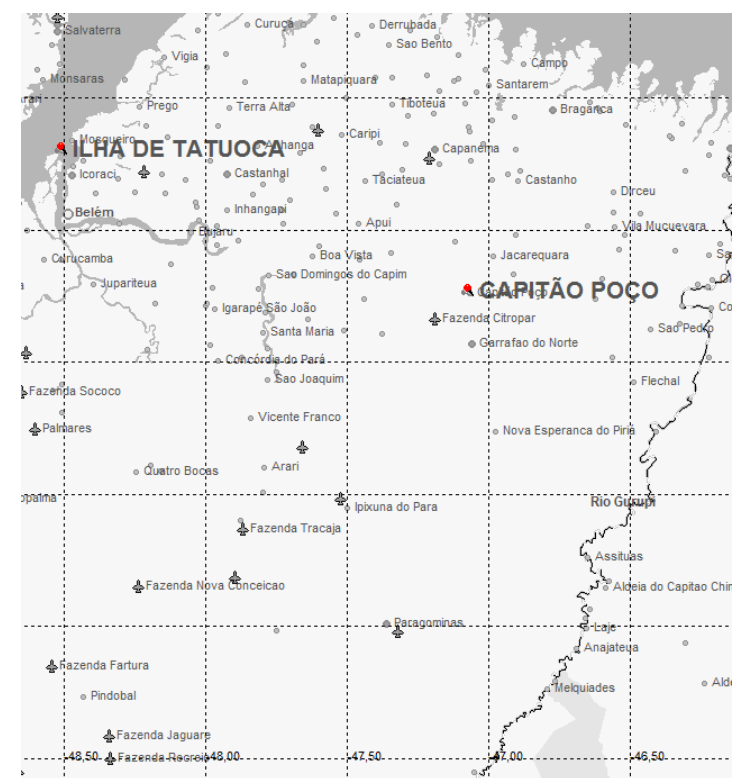

Figura 2 - Localização geográfica de Capitão Poço e Ilha de Tatuoca, onde está situado TTB.

Os registros dos dois observatórios escolhidos, seguem o padrão IAGA, ou seja, seus sensores são do tipo vetorial e alinhados com as componentes $(H, D, Z)$ do campo 
magnético local. Os registros tem período padrão de 1 minuto.

\section{Resultados}

Nos primeiros resultados para esta análise, para o dia 24/11/2008, foi um dia magneticamente calmo. Na estação de Capitão Poço a média do campo no dia, foi de $26595,12 \mathrm{nT}$, o valor mínimo que ocorreu às 00:43 horas foi de 26573,43 nT enquanto o valor máximo correspondente a 26649,29 nT foi observado às 15:20 horas. A amplitude máxima foi de 75,86 nT. Segundo o IGRF o campo médio na coordenada e altitude correspondente foi de 26532,9 nT se aproximando do campo medido, com um erro de 62,22 nT, sendo este muito pequeno, próximo a $0,23 \%$, o que valida as medições feita em campo.

A variação diurna é bastante semelhante entre Capitão Poço e TTB, explicado pelo fato de estarem situadas não muito distante, conforme pode ser observado pelas figuras 3a e 3b para o dia 24 de novembro de 2008.
$3 a$

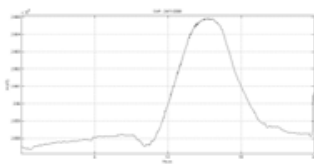

$3 b$

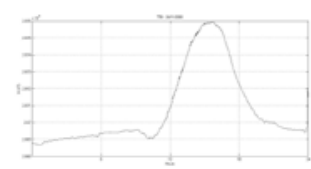

Figuras 3a e $3 b$ mostram a variação diurna, de $\mathrm{H}$, em Capitão Poço e TTB no dia 24 novembro de 2008.

Entretanto neste mesmo dia pode-se ver, pela figura 40 registro em VSS. As intensidades, os máximos e mínimos ocorrem de maneira bastante diferentes.

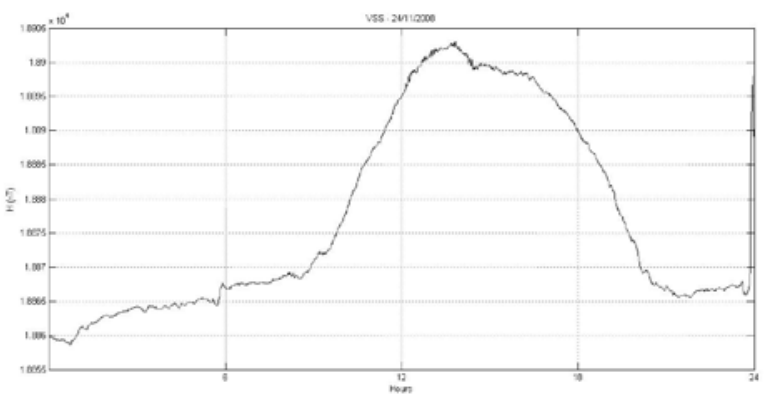

Figura 4 variação diurna de $H$ registrada em 24 de novembro em VSS.

As etapas de identificação e classificação das variações geomagnéticas de $\mathrm{H}$ e Z, nos diferentes locais estão sendo analisadas e serão apresentadas durante o simpósio. Por exemplo, no dia 24 de novembro de 2008 , um dia magneticamente calmo, sendo possível notar variações do tipo SI iniciada por um impulso súbito às 5:43 horas seguido de alguns pulsos sem muita variação da atividade. Estas variações com amplitude média de $3,92 \mathrm{nT}$, possivelmente se encerra às 09:17 horas.

\section{Discussão e Conclusões:}

Este estudo está em fase de execução e na apresentação no $V$ Simpósio serão apresentados resultados atualizados.

\section{Agradecimentos}

Agradecimento ao CNPq, através do Programa de Iniciação Cientifica do ON pela concessão de bolsa para a aluna.

\section{Referências}

Amarante, J. A. A. de 1967. Guia para a identificação e classificação das Variações Geomagnéticas de Curta Duração. Comissão Nacional de Atividades Espaciais. 29 pags.

Chandra, H., Simha, S. e Rastogi, R.G. de 2000. Equatorial Electrojet Studies from Rocket and ground measurements. Earth Planets Space, 52 , p 111-120.

Knapp,G. D.; Hurwitz,L.; Nelsom, H. J. de 1962. Magnetism of the Earth. U.S. Departam ent of Commerce.

Rastogi, R.G.; Kitamura, T. and Kitamura, K. de 2004 Geomagnetic Field Variations at the Equatorial Electrojet Station in Sri Lanka, Peredinia - Annales Geophysicae. p 2729 - 2739

Shume, E.B.et al de 2010. Variabilities of the equatorial electrojet in Brazil and Perú. Journal of Geophysical Research, Vol 115, A06306 p 1-9.

Forbush, S. E.e Casaverde, M. de 1961 - Equatorial Electrojet in Peru- Canegie Instituition of Washington Publication 620. 